\title{
Perspectivas sobre el mundo de trabajo femenino durante el peronismo clásico
}

\author{
Autora: Carolina Barry (PHD Ciencia Política) \\ Universidad Nacional de Tres de Febrero \\ Consejo Nacional de Investigaciones Científicas y Técnicas \\ Dirección: Avda. Santa Fe $8308^{\circ}$ piso \\ Ciudad de Buenos Aires \\ Argentina \\ cbarry@fibertel.com.ar / cbarry@untref.edu.ar
}

El mundo del trabajo durante el peronismo* ha sido fuente de numerosas e importantes investigaciones debido, entre otras razones, al novedoso conjunto de medidas que se aplicaron a partir de 1943 relacionadas con el movimiento obrero. También, por el desarrollo sindical que formó parte de las políticas de estado implementadas por Juan Domingo Perón, primero como director del departamento de Trabajo y Previsión -pronto transformado en ministerio- y luego, como presidente de la Nación y líder popular indiscutido. Uno de los rasgos más singulares del peronismo es la originalidad de albergar en su seno un doble liderazgo carismático: un líder, Juan D. Perón, y una líder, Eva Duarte de Perón -Evita-. Desde mediados de 1947 hasta su muerte en 1952, la Argentina contó con dos líderes que se complementaron, aunque los orígenes y la naturaleza de su poder fueron distintos. El liderazgo de Perón ya estaba establecido cuando asumió la presidencia de la Nación y el de Eva Perón se fue desarrollando una vez que él estuvo en el poder. Los puntales de la construcción política de Evita, sintéticamente, fueron la relación directa y estrecha con los sindicatos, la creación de la Fundación Eva Perón, la sanción de la Ley de Sufragio Femenino y el Partido Peronista Femenino. ${ }^{1}$

El estado del conocimiento sobre los trabajadores y las estructuras sindicales durante el peronismo ha atravesado una serie de avatares en su tratamiento y abordajes. Estudios generales sobre el tema, precursores y cardinales fueron realizados sobre los sectores obreros y sindicales en general. ${ }^{2}$ En la actualidad, se observa un viraje hacia un nuevo escenario en el que, el foco del debate se ha trasladado de los sociólogos a los historiadores, de las perspectivas macro a las micro y de lo político a lo social, según la observación de Raanan Rein. ${ }^{3}$ Por otra parte, el énfasis inicial acerca de la supuesta ruptura y anomalía que representaba el peronismo ha desaparecido prácticamente a favor de la continuidad y de su contextualización en el proceso histórico argentino. La imagen homogénea ha sido reemplazada por un cuadro complejo y heterogéneo. Es así como los grandes temas generales y globales están dando paso a la escala pequeña. En forma simultánea, la dimensión nacional, basada en la experiencia metropolitana, ha dado lugar a distintas miradas provinciales, regionales y locales.

Respecto al mundo del trabajo femenino en general existen trabajos cardinales ${ }^{4}$. El peronismo, por un lado, y los estudios sobre género y mujeres, por otro, se han convertido en los últimos tiempos en objeto de estudio de varias áreas y ha originado debates multidisciplinarios,

\footnotetext{
* Una versión previa de este artículo ha sido publicado por la revista Investigaciones y Ensayos, Academia Nacional de la Historia (Buenos Aires 2011).

1 Sobre la construcción política de Eva Perón ver Barry, Carolina, Evita Capitana, el Partido Peronista Femenino 1949-1955, Eduntref (Buenos Aires 2009).

${ }^{2}$ En ese sentido son indiscutibles, entre otros, los trabajos de Gino Germani (1962), Política y sociedad en una época de transición; Juan Carlos Torre (1990) Perón y la vieja guardia sindical ; Daniel James (1988) Resistencia e integración, peronismo y las clases trabajadoras argentinas, 1946- 1976; Hugo del Campo (1983), Sindicalismo y peronismo. Los comienzos de un vínculo perdurable; Louise Doyon (1984) Organized Labor and Perón, 1943-1955; Walter Little (1979), "La organización obrera y el estado peronista, 1943-1955".

3 Raanan Rein, Carolina Barry, Omar Acha y Nicolás Quiroga, Los estudios sobre el primer peronismo: Aproximaciones desde el siglo XXI, Instituto Cultural de la Provincia de Buenos Aires (La Plata 2009).

${ }^{4}$ Ver Mirta Lobato, Historia de las trabajadoras en la Argentina (1869-1960), Edhasa (Buenos Aires 2007). De la misma autora, La vida en las fábricas: trabajo, protesta y conflicto en una comunidad obrera. Berisso, 1904-1970, Prometeo (Buenos Aires 2004). Dora Barrancos, Mujeres en la sociedad argentina. Una historia de cinco siglos, Sudamericana (Buenos Aires 2007).
} 
observándose, en los últimos años, investigaciones en cantidad y complejidad de análisis que hacen al rol de la mujer. Aunque no tienen como objetivo el análisis específico de este sector laboral durante el peronismo. Lo más delimitado en material social, con ciertas implicancias en lo laboral, aunque no conclusivo, es una compilación publicada junto a dos colegas sobre la Fundación Eva Perón y las mujeres. En el cual se revisan los ámbitos de injerencia y atribuciones que disputaron las reparticiones estatales y la Fundación Eva Perón respecto de las políticas femeninas. Además, permite brindar líneas para continuar profundizando las características que asumieron las políticas sociales y laborales. Dicho de otra manera, se aprecia una vacancia en los temas relativos a las trabajadoras durante el peronismo.

Este artículo es producto de nuevas reflexión y preguntas que surgieron, como señalé anteriormente, en forma posterior a la publicación del libro La Fundación Eva Perón y las mujeres, editado en 2008. ${ }^{5}$ En ese sentido, algunas cuestiones guiarán a otras: ¿sobre qué sectores operó la Fundación Eva Perón? ¿Sobre los que se encontraban por dentro o fuera del mundo del trabajo? ¿Implementó una política de protección a mujeres o sólo a las madres? En este sentido, ¿podría decirse que estableció una ruptura? ¿Consideró el peronismo una forma particular de trabajo femenino? ¿El discurso fue consecuente con la práctica? Estas y otras, preguntas proponen buscan puntear una arista distinta que nos permita acercarnos a las implicancias reales y simbólicas del mundo del trabajo femenino durante el peronismo. También, realizar algunas consideraciones y reflexiones sobre las políticas sociales y laborales aplicadas a este universo. Este trabajo se inscribe dentro de uno más amplio y específico, relacionado con las mujeres durante ese período. El objetivo es abordar las políticas sociales exclusivas para las mujeres implementadas por la Fundación Eva Perón (FEP) y examinar, a partir de la bisectriz del trabajo, las poblaciones, valoraciones y, también, las posibles tensiones vinculadas con las mujeres. Es decir, entrecruzar "lo social" con "lo laboral" e indagar en las derivaciones que de este entrecruzamiento se producen. El juego interpretativo buscará encontrarse en alguna frontera en la que confluyan ambos espacios

Un amplio espectro de las decisiones del Estado puede ser considerado políticas sociales no obstante se encuentren ligadas con las políticas públicas. A su vez, ha adoptado formas específicas en las distintas sociedades y regímenes políticos a lo largo de la historia. Las políticas sociales, en general, son mecanismos de integración social que apuntan a resolver cuestiones ligadas con el mundo del trabajo, la seguridad social, como también aspectos referidos a la educación, la salud y desarrollo y mejoramiento urbano. ${ }^{6}$ El concepto asistencia social envuelve un conjunto extraordinariamente variado de prácticas que se inscriben no obstante en una estructura común, determinada por la existencia de ciertas categorías de poblaciones carecientes y por la necesidad de hacerse cargo de ellas. El sentido de las políticas sociales es asegurar el orden público y preservar el equilibrio social. Éstas podrían seguir dos vías, una relacionada con el centro, es decir, sobre las principales variables de integración social (vinculadas al trabajo); y la otra, en los márgenes, es decir, sobre las personas que no pueden acceder a la integración a través de los mecanismos anteriores, es decir, sobre los sectores que quedan en la periferia y actúan como compensatorias de la falta de acceso al mercado de trabajo, que son las que examinan integraciones alternativas parcial o totalmente tuteladas. ${ }^{7} \mathrm{~A}$ su vez, podríamos dividir las políticas compensatorias en la entrega de bienes o dinero, o la prestación de servicios mientras se busca restaurar la reinserción laboral. Al grupo conformado por los beneficiarios de estas políticas se le suman también aquellos que, teniendo trabajo, cuentan con un nivel de ingreso tan bajo que se los podría considerar indigentes

¿En qué áreas actuó el Estado durante este período? De acuerdo con los estudios realizados, el peronismo cambió la lógica de intervención y consolidó su intervención en el centro a partir de una serie de medidas laborales tendientes a proteger a los trabajadores en conjunto. Pero al mismo tiempo, operó sobre los márgenes con políticas novedosas de asistencia

\footnotetext{
5 Carolina Barry, Karina Ramacciotti, y Adriana Valobra, La Fundación Eva Perón y las mujeres, entre la provocación y la inclusión, Biblos (Buenos Aires 2008).

${ }^{6}$ Juan Suriano, (comp), La cuestión social en Argentina, 1870-1943, La Colmena (Buenos Aires 2004).

${ }^{7}$ Robert Castel, Las metamorfosis de la cuestión social. Una crónica del salariado, Paidós (Buenos Aires 1997.
} 
social planteadas como un derecho ciudadano y de deuda pública. ${ }^{8}$ Plotkin observa que, si bien los sindicatos crecieron en forma significativa durante los dos primeros gobiernos peronistas, hacia 1954 los porcentajes de afiliación de trabajadores rurales y urbanos alcanzaban el $42 \%$, vale decir que más de la mitad de los asalariados quedaba fuera de dichas estructuras. El autor agrega que la FEP actuó como contrapeso del poder sindical. ${ }^{9}$ Se podría inferir que el Estado estuvo a cargo del centro, y la FEP, de los márgenes. Ahora bien, no se puede considerar el alcance de la función de los sindicatos como un sistema de protección y asistencia social cuando estos todavía estaban en proceso de formación y consolidación; ser alcanzado por el poderoso sistema sindical no traía consigo la institución de los grandes aparatos de protección social que devinieron en los años posteriores, si bien ya en 1944, el Instituto Nacional de Previsión Social contemplaba armar esquemas asistenciales, de salud y vivienda social. Durante el primer peronismo, lo que singularizó al amplio mundo del trabajo fue la significativa afiliación sindical alcanzada, y la alianza entre el Estado y los sindicatos, buscando mayores salarios, pleno empleo, mediación en conflictos. El bienestar social quedó, en parte, en manos del Estado y, en especial, de la FEP. El peronismo implementó políticas sociales destinadas a incorporar a los sectores marginales de la sociedad a la esfera del Estado; para ello, la herramienta más importante que utilizó fue la FEP. ${ }^{10}$ Sin embargo, la misma lógica de funcionamiento de esta institución, según la cual lo discrecional y lo pragmático eran ley, condujo a que abarcara a amplios sectores de la población, trabajadores y no trabajadores. Se podría inferir que no se trató de un proyecto congruente y homogéneo al servicio de una ideología clara. Zanatta observa que se trató de un plan de construcción de una nueva cristiandad, compartido por la Iglesia y el ejército, que incluía la voluntad de integrar al pueblo mediante una política de reformas sociales de tono populista. Para ello, en la elaboración de este proyecto, el peronismo se valió de hombres clave pertenecientes a dicho sector. ${ }^{11}$

La FEP tuvo una notoria función social, de la que se desprende también un contenido fuertemente político. Su inscripción se torna compleja, pues si bien su estatus era privado, actuaba en forma paralela, por encima o valiéndose del Estado. O, en palabras de su fundadora, como un apéndice del gobierno destinado a cubrir las lagunas y complementar la acción estatal. ${ }^{12}$ Una investigación preliminar permite afirmar que la FEP confirió una especial atención a la protección e inclusión de mujeres y niños y que, a excepción de los hogares de ancianos, ninguna estuvo destinada a promocionar políticas privativas para varones. Es probable que se contemplara la incipiente acción de las obras sociales sindicales para su abordaje. Si hacemos un paneo sobre las principales instituciones y políticas aplicadas por la FEP se puede observar que el sector de mayor interés y sobre el cual se profundizaron las políticas fue la infancia, ${ }^{13}$ cuya atención se prestó respecto de dos temas centrales: la educación y la salud, para lo cual contó con establecimientos de distinto tipo a lo largo de todo el país. Las mujeres siguieron en orden de importancia, con tres instituciones emplazadas en la ciudad de Buenos Aires. Esto produjo, como consecuencia, una discriminación por sexos, por necesidades sociales y sobre quiénes era perentorio asistir. De cualquier manera, la FEP implementó políticas sociales y sanitarias destinadas a toda la población, como por ejemplo, la labor de las células mínimas, el Tren Sanitario, hospitales, turismo social, vivienda, pensiones, el plan agrario, entre otras.

\footnotetext{
${ }^{8}$ Julián Bertranou; Juan Manuel Palacio y Gerardo Serrano, El País del no me acuerdo, Prometeo (Buenos Aires 2004).

${ }^{9}$ Mariano Plotkin, Mañana es San Perón. Propaganda, rituales políticos y educación en el régimen peronista, Ariel (Buenos Aires 1994).

${ }^{10}$ Martín Stawski, Asistencia social y buenos negocios. La Política de la Fundación Eva Perón, Imago Mundi, (Buenos Aires 2008)

${ }^{11}$ Loris Zanatta, Del estado liberal a la nación católica. Iglesia y ejército en los orígenes del peronismo. 1930-1943, UNQ (Buenos Aires 1996).

${ }^{12}$ Eva Perón, Mensajes y Discursos, FUPT - FIEHP (Buenos Aires 1999). Discurso pronunciado el 5 de diciembre de 1949.

${ }^{13}$ Ver Donna Guy, Women Build the welfare state in Argentina, performing charity and creating rights in Argentina, 1880-1955. Duke University Press. (Durham 2009).
} 
En el caso de las mujeres, las políticas sociales pueden valorarse en diversos planos: el del trabajo, el de la reproducción cotidiana, la maternidad y la salud. En este trabajo dejaré de lado cuestiones referidas a la FEP, en general, que ya han sido abordadas por diferentes investigaciones y me ocuparé exclusivamente de las tres instituciones privativas para mujeres: Hogares de Tránsito, Hogar de la Empleada y Escuela de Enfermeras para, a partir de allí, realizar una mirada transversal que permita dar respuesta a los interrogantes planteados.

\section{Definiendo poblaciones: la bisectriz del trabajo}

El mundo del trabajo durante el peronismo ha sido fuente de numerosas e importantes investigaciones. Es un tema que posee numerosas aristas y una complejidad de la que no se desprende un análisis profundo e independiente sobre varones y mujeres. Durante el periodo cobró importancia la protección de los sectores trabajadores, y en especial la redistribución del ingreso que afectaba a ambos sexos. Los convenios colectivos mantuvieron las diferencias salariales entre varones y mujeres, aunque la brecha disminuyó. ${ }^{14}$ El Censo Nacional de $1947 \mathrm{e}$ investigaciones cardinales sobre el tema permiten arrimarnos al abanico ocupacional de las mujeres. De allí se desprende que un número significativo se encontraba ligado al sector servicios, de hecho, el más amplio de la ocupación femenina. Las variaciones dentro del campo involucraban al servicio doméstico, empleadas públicas, telefonistas, docentes. A este panorama debe sumarse la acentuación en la educación formal y su derivación en empleos con mayor calificación. El sector fabril siguió en importancia, como también el comercio. El agropecuario contaba con una quinta parte de las trabajadoras, entre quienes no se pueden dejar de contemplar las particularidades regionales. Así por ejemplo, en Santiago del Estero, las mujeres acompañaban a sus maridos en el obraje, mientras un número significativo se dedicaba al servicio doméstico, con las consecuentes implicancias migratorias. ${ }^{15}$ El índice de sindicalización fue significativo; es destacable la creación de la Comisión Auxiliar Femenina de la CGT, aunque no se aprecian destacadas figuras femeninas.

Los primeros esbozos de intervención social sirvieron para colocar, poco a poco, las bases del proyecto político que eclosionaría años más tarde; para delimitar las prácticas y también para discriminar la población sobre la cual intervenir. El tema del trabajo de las mujeres había sido un punto de ocupación y preocupación desde fines del siglo XIX. La principal razón estaba relacionada con el peligro que entrañaba el consecuente abandono de sus obligaciones, como también su exposición a la deshonra. El eje de la discusión de las reformas políticas y sociales de las primeras décadas del s XX estuvo centrado en la maternidad y la protección de la madre obrera. ${ }^{16}$

Durante el peronismo se sancionaron numerosas leyes laborales que contemplaban a la familia del trabajador; las relaciones laborales estaban reguladas por la intervención del Estado, a través de la Secretaría primero y luego con el Ministerio de Trabajo, creado en 1949. En lo relativo y específico del mundo femenino, se presentaron líneas no del todo claras. En agosto de 1944, la Secretaría de Trabajo y Previsión creó la División de Trabajo y Asistencia de la Mujer, novel organismo en el Estado, cuyo objetivo fundamental fue procurar la solución de todos los problemas sociales, morales y económicos de la familia considerando en modo especial aquellos que afectan a la mujer en su función de trabajadora y como la depositaria de "la elevada misión" de la maternidad. Los considerandos de la resolución de su creación marcaban el empeño de revalorizar a la familia, dentro de la cual la protección de la mujer ocupaba un lugar

\footnotetext{
${ }^{14}$ Mirta Lobato, op cit, 91.

${ }^{15}$ Marìa M. Tenti y Norma Salas, El movimiento obrero santiagueño en la gestión presidencial de Perón de 19461955, (Santiago del Estero 1995).

${ }^{16}$ Mirta Lobato, "El Estado y el trabajo femenino: el Departamento Nacional del Trabajo", en: Daniel Lvovich, y Juan Suriano, (ed.), Las políticas sociales en perspectiva histórica. Argentina, 1870-1952, UNGS - Prometeo (Buenos Aires 2006).
} 
preeminente, en especial cuando se veía obligada a trabajar. Los temas relativos a la mujer ocupaban el centro de la estructura funcional de la División que, a su vez, se fragmentaba en tres unidades: la primera apuntaba a temas netamente laborales (sindicatos, ramas de trabajo, seguridad laboral, salarios); la segunda, a la familia, de la cual uno de los puntos era específicamente el tema de la maternidad en función del trabajo, vale decir, protección y asistencia a la madre trabajadora; dentro de los temas de familia, un apartado señalaba "la natalidad", aunque sin mencionar alguna política específica al respecto; y la tercera, bajo el título "la cultura y la propaganda", dominaba temas relacionados con la capacitación de la trabajadora. Esta estructuración duró poco, y muchas de las funciones que tenía asignadas la División fueron absorbidas por otras ramas de la administración pública.

Una reestructuración en la Secretaría colocará a la División bajo la órbita de la Dirección General de Asistencia Social (DGAS), aunque los temas laborales continuarán dependiendo de forma directa de la Secretaría de Trabajo. La adquisición por parte de la Secretaría de Trabajo y Previsión de la DGAS no es un dato menor, como tampoco lo es la división que se plantea de los ámbitos de incumbencia del problema femenino: el laboral y el asistencial o de protección social. En 1948 se crea la Dirección Nacional de Asistencia Social, que dependía de la Secretaría de Trabajo y Previsión, una de cuyas funciones era proteger a madres desamparadas; la actuación de esta dependencia se vio opacada por la cada vez más presente acción de Eva Perón en la ayuda social; mientras que en materia laboral el tema parecería haberse centrado en la maternidad a través de las Cajas ${ }^{17}$ y de la generalización de las primas por maternidad. ${ }^{18}$ Por otra parte, desde el área de Salud, la Dirección de Maternidad e Infancia luchó por mantener su espacio en las cuestiones relativas al "binomio madre e hijo" hasta que fue absorbida por otro espacio de poder: la FEP. ${ }^{19}$

En este primer acercamiento a la problemática del trabajo femenino desde el Estado, el tema central transitaba cuestiones laborales que se podían cruzar con la coyuntura de la maternidad. Dicho de otra manera, la función materna no eclipsaba, inicialmente, el resto de los temas referidos a la mujer; aunque fue adquiriendo más fuerza la centralidad de la mujer en la familia, en cuanto su función maternal. Es probable que se produjeran tensiones respecto de la manera de abordar la temática de la mujer, incluso dificultando su tratamiento, si se lo aislaba de la función netamente biológica. En efecto, el tema de la mujer parecería haber quedado localizado en la maternidad; aunque no debemos dejar de tener en cuenta que, simultáneamente, en materia de ciudadanía política los pasos se agigantaban.

Ahora bien, volvamos a la pregunta inicial: ¿dónde se situó la FEP y en qué lugar de este escenario fue ubicada la maternidad? Implementó una política social relacionada con el centro (con el mundo de trabajo femenino) o con los márgenes, es decir, compensatoria de quienes no podían acceder al mercado de trabajo. Las ideas de Evita sobre la mujer, observa Navarro, no tienen la fuerza de sus convicciones sobre Perón o la oligarquía, "como si no hubiera pensado demasiado en sus problemas y tampoco le importaran mucho". Incluso, subraya la autora que no fue sincera al referirse a ellas. ${ }^{20}$ Si tenemos en cuenta la población sobre la cual operó la FEP, esta afirmación requeriría algún tipo de matiz. Del total de instituciones destinadas a poblaciones específicas se observa que cinco concernían a las mujeres: tres Hogares de Tránsito, la Escuela de Enfermeras y el Hogar de la Empleada y, en forma indirecta, los hogares-escuela, y las ciudades Infantil y Estudiantil. Si bien estas instituciones se presentan insuficientes para incluir toda la problemática femenina, no podemos dejar de considerar que dentro del universo general de la FEP el tema de la mujer contó con un espacio privilegiado.

\footnotetext{
${ }^{17}$ En 1948, el número de inscripciones en la Caja ascendió a 751.698, mientras en 1942 las afiliadas sumaban 410.880. Es decir, en seis años el número prácticamente se duplicó. Lucila De Gregorio Lavie, La ciudadana, (Buenos Aires 1948), edición de la autora, 109.

${ }^{18}$ Alicia Garro y Horacio Gaggero: "La política de la seguridad social peronista", en: BERROTARÁN, Patricia, y otros Sueños de Bienestar en la Nueva Argentina, Imago Mundi (Buenos Aires 2004), 186.

${ }^{19}$ Carolina Biernat y Karina Ramacciotti, "Las madres y sus hijos en foco". En Carolina Barry y otras... 51 y ss.

${ }^{20}$ Marysa Navarro, Evita, Corregidor, (Buenos Aires 1981), 228.
} 
En ese sentido, los tres abordajes aparecen claramente destinados a instancias relacionadas con el trabajo: la carencia, la capacitación y la protección. A grandes rasgos, podemos decir que la Escuela de Enfermeras se ocupó de capacitar laboralmente a un sector femenino; el Hogar de la Empleada buscó alojar a las trabajadoras provenientes de las provincias; y los hogares de tránsito, de proteger y buscar políticas de inclusión social a un sector en estado de carencia. La otra bisectriz que corta estas instituciones es la maternidad, que incluía, además, una dimensión moral. Veremos cómo estos cruces dan cuenta de la situación de las mujeres en la FEP y de una aproximación al universo laboral femenino considerado por el peronismo.

\section{La formación laboral}

La enfermería fue la única iniciativa de capacitación profesional propiciada directamente por la FEP. Durante el período peronista el trabajo femenino aumentó, ${ }^{21}$ y la enfermería ocupó un lugar destacado. En ese sentido, las escuelas abiertas durante el peronismo, la del Ministerio de Salud y la de la FEP, estaban en consonancia con un espíritu de época de brindar mayor profesionalización y feminización a dicha actividad, producto de necesidades puntuales y encaradas, incluso, como política de Estado. Se inscribe en un período en el cual se intenta mostrar un organismo eficaz, cercano a la salud de las masas, y en la necesidad de ampliación de servicios sanitarios en un momento de redistribución económica. Estas dos escuelas han sido analizadas por Ramacciotti y Valobra (2008), de cuyo estudio querría tomar una serie de puntos a los fines de este trabajo.

En primer lugar, la FEP tuvo una marcada intención de capacitar a mujeres, no necesariamente de sectores humildes o más vulnerables. Este recorte de clase implicaba no sólo la calificación profesional, sino también lograr un medio de vida digno. Las aspirantes a enfermeras debían cumplir con una serie de requisitos: estudios primarios completos (aunque en un primer momento éste no fue necesario), tener entre dieciséis y veintiún años de edad, gozar de buena salud física y contar con un certificado de buena conducta. Los estudios y la buena salud dan cuenta de que no se trataba de mujeres de sectores muy pobres, sino de los sectores medio y medio-bajo, quienes podían contar con instrucción y buena alimentación que se tradujera en fortaleza física. La edad, sin dudas, vincula, veladamente, a mujeres solteras y sin hijos, condición que otras escuelas marcaban como excluyente; el último requisito no puede sino referirse a su conducta moral. Por otra parte, si bien no se buscó un estereotipo físico determinado, implícitamente estaba dado por la "belleza" llamativa de sus integrantes más visibles; como rezaba el "Canto a la enfermera argentina": "niña hermosa... digna de ser siempre imitada".

Una vez constatados los requisitos manifestados, la institución se hacía cargo de la alumna en forma total, ya que en ella se cultivaban también los valores espirituales cristianos. Una vez ingresadas, la capacitación que recibían no se limitó sólo a temas médicos sino también políticos, deportivos y "modernos", como por ejemplo, manejar autos o motos. A partir de 1953, se incluyó el adoctrinamiento partidario. Como se presumía que su intervención estaría cruzada por contextos político-sociales delicados, se las preparaba para actuar ante un conflicto bélico o perturbaciones internas como huelgas generales, y como agentes de ayuda ante catástrofes ocurridas, incluso, en otros países. Los anuncios para la inscripción en la Escuela decían: "Amor al prójimo: demuéstrelo en la Escuela de Enfermeras de la Ayuda....". 22 Podían especializarse en temas netamente técnicos, como auxiliares de anestesista o transfusionistas, e instrumentistas.

Ahora bien, ¿cuál era el perfil laboral de estas mujeres? En principio, no escapaban a la misión de servicio que lleva implícita la profesión, vale decir, la abnegación, el sacrificio, el altruismo, entre otras muy femeninas, por cierto. Pero al mismo tiempo se trataba de mujeres jóvenes, sanas, fuertes, valientes, disciplinadas, adoctrinadas, dispuestas a manejar un jeep, motoneta o trabajar con perros adiestrados, como también, a tratar con naturalidad los cuerpos y

\footnotetext{
${ }^{21}$ Noemí Girbal-Blacha, Noemí, "El hogar o la fábrica. De costureras y tejedoras en la Argentina peronista (19461955)", en: Revista de Ciencias Sociales No 6, (Quilmes 1997) pp. 217-230.; Mirta Lobato, op. cit.

${ }^{22}$ Democracia, Buenos Aires, 20 de febrero de 1949.
} 
los sufrimientos del otro, capacitadas para actuar en emergencias de distinto tipo. No se trataba de mujeres cualesquiera. Sus funciones se entonaban, también, al ritmo de la política. Poco tienen que ver estas representaciones con las frágiles y desmayadizas muchachas de los culebrones de las revistas. Las características de la capacitación laboral femenina desde la FEP no dejan de ser llamativas, ya que, si bien podemos pensar que se trataba de contar con personal propio de la institución, también pareciera que su función trascendía a ésta.

Un detalle para tener en cuenta son los desfiles en que participaron sus integrantes, y los uniformes utilizados. En ellos, estas mujeres proyectaban la imagen de una organización más de tipo militar que sanitaria; una suerte de milicia para esta organización, la FEP, que en muchos puntos se asemejaba a un Estado, como señalamos arriba. Participaron en el desfile de Reservistas, una actividad, hasta ese momento, netamente masculina y que por primera vez contó con mujeres en sus filas. Los reservistas son aquellos que contaron con formación militar pero volvieron a la vida civil, quedando en "reserva". Los hombres asistían con uniforme militar. Las enfermeras participaron de este desfile con un despliegue descomunal, y ostentando un uniforme de tipo castrense. Un dato más que conduciría a una conclusión, quizás riesgosa, fue la adquisición en 1951, por parte de la FEP, de 5.000 pistolas y 1.500 ametralladoras para que, en caso de otro levantamiento militar, los obreros pudieran defender a Perón. También es para tener en cuenta que en 1955, las directoras de los hogares de la FEP fueron entrenadas en la escuela de Tiro Federal y que recibieron pistolas para defenderse en caso de ataques; lo que provee un ángulo más para el análisis del mundo del trabajo femenino visto desde la Fundación.

Esta fue la única instancia de profesionalización femenina dentro de la FEP. Otra organización evitista también contó con capacitación laboral para las mujeres: las unidades básicas del Partido Peronista Femenino. Allí podían adquirir distintos oficios, o conocimientos generales de varias tareas. ${ }^{23}$ Pero no obtenían un título que diera cuenta de su capacitación, como sí lo tuvieron las enfermeras.

\section{Las trabajadoras}

La otra aplicación de políticas sociales de la FEP en relación directa con el trabajo fue el Hogar de la Empleada. Su nombre habla por sí sólo, siendo su objetivo principal alojar y proteger a las obreras y empleadas provincianas que no tuvieran familia en la Capital. A su vez, estas mujeres debían contar con buena salud previo chequeo médico y visita de la asistente social para "acreditar la conducta llevada en la vida", pues podía tornarse un peligro para sus futuras compañeras. Omar Acha (2008) estudió este establecimiento y a su par católica, la Casa de la Empleada, y marca las similitudes y diferencias entre ambas instituciones. A los fines de este trabajo, me interesa hacer algunas observaciones respecto de la institución evitista. El Hogar aspiraba a "cuidar con amor el rostro fecundo del futuro"; cuidar a las trabajadoras de los posibles "engaños" que pudieran sufrir, se sobreentiende que por parte de hombres inescrupulosos que deshonraran a su futura descendencia. Se preguntaba un folleto de propaganda de la FEP, “¿acaso las muchachas que trabajan no son justamente el potencial más fecundo de la humanidad?". El tema de la maternidad y la moral entrecruza sin clemencia el trabajo femenino, al que no escapó este Hogar. La alimentación que se brindaba, tanto para las moradoras como para las que acudían especialmente para "comer bien y a precios económicos", pretendía no sólo facilitar su nutrición, sino también su consecuente fortalecimiento físico, para asegurar una descendencia acorde y no "enfermiza y débil". ${ }^{24}$ El Hogar intentaba contemplar todos los problemas que debía enfrentar la trabajadora, donde sentimientos como la soledad y la tristeza entrelazan la situación de estas jóvenes "que esperan" a quien las ame debidamente. Pero para eso también había que preservar las buenas costumbres, entre las que se encontraban la restricción del acceso a los novios o pretendientes, aunque más no fuera para una visita ocasional. A ellos se los debía despedir a unas cuadras, alejando aún más la mirada escrutante del zaguán familiar.

\footnotetext{
${ }^{23}$ Carolina Barry, 2009, op cit.

${ }^{24}$ De Gregorio Lavie..., op. cit., 105.
} 
La justicia que el gobierno les otorgaba, mediada por el "Hada Buena", dista mucho de las imágenes oscuras de luchas, esfuerzo y sufrimiento que simbolizaban la iconografía comunista o franquista, y entre ellas se puede observar una contraposición de antípodas ideológicas. El rostro angustiado, los cuerpos desgarbados, los pechos flácidos eran el resultado de la degradación del esfuerzo laboral cotidiano, de la explotación. ${ }^{25}$ Las enfermeras y las empleadas no sólo se mostraban bonitas sino que también sonreían alardeando alegría. En el peronismo, y en especial en la FEP, las imágenes ofrecen un aspecto alegre, gozoso, de bienestar y felicidad. La estética, la sonrisa y la alegría cobran una suerte de valor político. Lo feo deshonra y marca a quien lo recibe: "es lo merecido". Por el contrario, lo lindo, lo agradable, considera y dignifica a quien lo acoge.

Las trabajadoras que vivían o se alimentaban en el Hogar convivían con un lujo exacerbado. Una suntuosidad innovadora, caracterizada por Anahí Ballent como una arquitectura del exceso o como la estética kitsch. ${ }^{26}$ Se podría pensar en una empleada de Harrod's, por ejemplo, quien, luego de una ardua jornada laboral, se alojaba en un sitio acaso superior en lujo y comodidades que el de las displicentes clientas que gastaban sin reparo ante su atónita mirada. Poco tenía que ver con la situación de otras empleadas u obreras. Esta misma muchacha contaba en el Hogar con un espacio destinado al esparcimiento como también al consumo, con la reproducción de la calle Florida donde adquirir artículos sin necesidad de moverse del Hogar y fuera de los peligros de la ciudad. Estas imágenes operaban como una reapropiación de otras ya existentes, al tiempo que se ostentaban como un derecho. Mientras tanto, la política se filtraba no sólo en esta impronta ideológica, sino también en la presencia de las imágenes de los líderes del peronismo en numerosos espacios del Hogar, como ser la cabecera de las camas de las alojadas.

Podría pensarse que el Hogar se presenta también como un premio o estímulo para la trabajadora que cumplía con los requisitos de admisión, uno de los cuales era no tener hijos. Es decir, la madre no debería trabajar; aunque desde lo discursivo se planteara que la madre o una figura femenina pueden ocuparse tanto de los quehaceres domésticos como de trabajar fuera del hogar al mismo nivel y con la misma capacidad que el hombre. Incluso se menciona que la conquista de los derechos políticos la iguala con el varón en la posibilidad de ser elegida para un puesto público. ${ }^{27}$ Otro estímulo a la trabajadora fueron los concursos de elección de la Reina del Trabajo, "nuestras lindas obreritas" 28 . Retomando las características de los hogares, se observan lugares comunes en relación con las analizadas para la Escuela de Enfermeras, por ejemplo, la juventud, la moral, la ausencia de hijos, el manejo del ocio y la salud. Esta división de poblaciones operaba en lo que se ha denominado el centro, es decir, sobre el mundo del trabajo.

\section{El otro lado de la bisectriz: la alfombra persa}

\section{a) Poblaciones}

Todo el cúmulo de situaciones que no eran contempladas en las dos instituciones mencionadas hallaba su refugio en los tres hogares de tránsito: el mundo de la ausencia de trabajo, y por ende, la carencia y la exclusión. Allí no se exigía dar cuenta de su "comportamiento en la vida", ni de salud, ni educación, ni trabajo, y en ellos la contingencia de la maternidad era una cuestión más a tener en cuenta dentro de la gravísima problemática general. Ellos eran una suerte de alfombra bajo la cual se colocaba la miseria; pero se trató de una alfombra "persa" y, como tal, había que mostrarla. Dejando de lado las alegorías, ¿qué políticas se aplicaron en los sectores femeninos que estaban fuera del mundo del trabajo cuya consecuencia era la pobreza extrema o el riesgo de desafiliación? Castel define la desafiliación como una ruptura en las redes de integración primaria, cuando el conjunto de las relaciones de

\footnotetext{
${ }^{25}$ Mirta Lobato, op cit.

${ }^{26}$ Anahí Ballent, Las huellas de la política. Vivienda, ciudad, peronismo en Buenos Aires, 1945-1955, PrometeoUNQ, (Buenos Aires 2005)

${ }^{27}$ Conocimientos básicos. Serie para $5^{\circ}$ grado. La Mujer Argentina en el Trabajo (1950), Buenos Aires, Kapelusz.

${ }^{28}$ Sobre este tema, ver Lobato, (2005), op. cit
} 
proximidad que mantiene un individuo sobre la base de su inscripción territorial, que es también una inscripción familiar y social, sufre una falla que le impide reproducir su existencia y asegurar su protección. ${ }^{29}$

Es aquí donde la política social de la FEP asomó con toda su furia. La Fundación abrió tres hogares de tránsito en la ciudad de Buenos Aires durante 1948. Estaban habitados por mujeres y sus hijos. Los maridos, parejas e hijos mayores de 14 años se alojaban en un Instituto Municipal, donde sólo podían pasar la noche y en el cual recibían un subsidio temporario. Ellos tenían prohibida la entrada a los hogares, excepto en situaciones extraordinarias. Desde un inicio, la FEP procuró llegar a una franja de mujeres en vías de socialización. La respuesta fue un conjunto de medidas destinadas a promover su integración y protección. El perfil social sobre el que se llevarían a cabo las políticas sociales mostraba que no sólo se tenía en cuenta la ausencia de recursos económicos que imposibilitaba la subsistencia, sino también la privación de medios, de capacidades, de posibilidades de revertir sus propias situaciones personales y familiares. La carencia no sólo tiene que ver con la ausencia de recursos materiales o intelectuales, sino también culturales.

Las condiciones de las mujeres alojadas en los hogares eran la pobreza extrema o indigencia, junto con escasos niveles de sociabilidad y de instrucción, desnutrición, falta de empleo, de vivienda, de acceso a la salud y dificultad de ocuparse de la supervivencia de sus propias familias. La tipificación fue la siguiente: madre soltera, madre abandonada, familia ilegalmente constituida, prole numerosa, niños anormales, ancianidad, invalidez, enfermedad crónica, tratamiento médico, desocupación, tránsito justificado e inmigrantes, falta de vivienda. Se trataba de sectores socialmente excluidos que se constituían, tal como los define Pierre Rosanvallon, como la sombra proyectada de los disfuncionamientos de la sociedad, producto de un proceso de desagregación. ${ }^{30}$ Sin embargo, si bien estos eran los sectores sobre los cuales se realizaría la intervención, también había casos que no respondían, estrictamente, a los perfiles descriptos. Provenían de todo el país, e incluso de países limítrofes. Las situaciones eran diversas y permiten apreciar la profusión de inconvenientes que sufrían los pobres en una sociedad de migración donde había trabajo pero también gran vulnerabilidad, sobre todo entre las mujeres. En ese sentido, los hogares se presentan como una institución muy flexible en términos de la población a la que pueden captar, lo cual da cierta eficacia al asistencialismo de la manera en que éste era concebido por Evita.

El hecho de que todos los hogares estuvieran en la Capital Federal permitía una mayor facilitación de recursos para resolver las cuestiones referentes a la salud. ${ }^{31}$ Las diversas problemáticas de la población a tratar permitieron definir poco a poco el objetivo final de los hogares: de uno muy ambicioso -como fue amparar a todos los menesterosos que deambulaban por la ciudad- pasó a las familias desvalidas, para circunscribirse finalmente sólo a las mujeres con o sin hijos. Si el objetivo inicial era alojar a los sin techo mientras se les buscaba ubicación, pronto se agregaron los servicios sociales y sanitarios. Por último, se añadió un servicio social más: la asistencia moral y espiritual.

\section{b) Puntales estratégicos}

Una de las características básicas de la asistencia social es que en esta instancia se da una construcción de conjunto, de prácticas de función protectora o inclusiva, y también preventiva. Un ligero punteo sobre las particularidades principales de éstas en la FEP nos acerca a las reflexiones sobre las que queremos profundizar. Las pautas de protección respondían a una forma de agregación social singular. Los fines de los hogares eran protección, amparo, rehabilitación social, inclusión, integración. Una de las características de lo social-asistencial es la localización de las prácticas. Esto representa una línea de fuerza importante para el desarrollo de lo social-asistencial que se dio de una manera singular en la FEP, dadas las peculiaridades del interior de los hogares, comenzando por su misma denominación. La armonía, la

\footnotetext{
${ }^{29}$ Robert Castel, op cit.

${ }^{30}$ Pierre Rosanvallon, La nueva cuestión social. Repensar el Estado providencia, Manantial (Buenos Aires 1995).

${ }^{31}$ Carolina Barry , "Mujeres en Tránsito", en La Fundación....
} 
ambientación, la decoración, exteriorizaban una apariencia agradable a la vista y formaban parte de los puntales estratégicos de las políticas de inclusión y protección de las mujeres y de la ideología que el peronismo les imprimió a las instituciones sociales, como señalamos anteriormente. Su estilo refinadísimo era provocativo e incitante, lejos estaba de ser una institución "fría y desalmada"; todo en el hogar era bello, pulcro, armonioso. La decoración no estaba librada al azar: los muebles y los adornos eran de una calidad superlativa para los estándares de entonces, y de la actualidad también. La estética era subversiva en todo el significado de la palabra; buscaba provocar en quienes allí se hospedaban una reacción, una respuesta; es decir, una acción conducente a desear cambiar sus existencias. Ballent plantea que la arquitectura del exceso era deliberada, cuanto más convencional y poco innovadora mejor cumpliría con su objetivo político: la reapropiación y resignificación de lo existente a quienes antes estaban excluidos de su goce. ${ }^{32}$ El lujo era entendido como reivindicación, y era una manera de politización de la acción social. Esta estética implicaba también un choque, y es probable que haya generado cierta perturbación en las mujeres; quizás el lujo las inhibiera, en especial porque en la mayoría de los casos no hacía más que dejar en evidencia sus infortunios.

La vestimenta también era parte de los símbolos de cambio para las mujeres. La indumentaria guardaba una estética muy especial propia de la época, parecía sacada de los figurines de moda. Los vestidos estaban diseñados y realizados con gusto, con el fin de "realzar todo lo posible la belleza femenina", y para evitar que, al usarlos, la mujer "se sienta disminuida o humillada". La exaltación o la búsqueda de la "belleza femenina" y de la familia en conjunto se pueden rozar con las reflexiones de Lobato acerca de las "Reinas del Trabajo", cuando señala que la relación entre rituales, belleza femenina y política conformó una densa malla que le dio forma a la cultura de masas durante el primer peronismo. ${ }^{33}$

El modelo ideal a imitar o a "ocupar" se asemeja al de los sectores medios y medioaltos y el estilo de vida recreado en los hogares buscaba confrontar con realidades muy diversas, por no decir con su extremo opuesto. Las imágenes dan cuenta de un estilo de vida de mujeres muy diferentes a las amas de casa o trabajadoras de las clases populares que debían desempeñar tareas múltiples en el hogar y fuera de él. El hogar de tránsito las presumía sentadas en bellos sillones, cómodas, rodeadas de sus hijos, leyendo o haciendo labores femeninas como tejido o bordados. Despreocupadas. Sin embargo, el hecho de confrontar y la ansiedad de ocupar realidades culturales tan diversas implicaban la apropiación de una cultura que se presentaba como alternativa, la de los sectores dominantes, que sin duda no era el reflejo de su propio estilo de vida.

La comida que en ellos se servía era un tema en sí mismo y mantenía las características de atención individualizada, teniendo en cuenta que la mayoría de las alojadas arrastraba generaciones de alimentación deficitaria. La médica elaboraba un plan nutricional que sobrepasaba las indicaciones dadas por el ministro de Salud Ramón Carrillo. ${ }^{34}$ Nada era más importante que la alimentación de las mujeres y los niños: la mujer, perpetuadora de la especie; los niños, el futuro.

El manejo de los hogares estaba a cargo de personal calificado, idóneo y preparado para el tipo de actividad que debían emprender. No se trataba de una intervención pasiva, sino que se apuntaba a superar las barreras que genera la pobreza estructural íntimamente ligada a carencias de infraestructura básica, salud, educación, y también a realidades particulares. Una suerte de imbricación entre lo macro y lo micro.

Las asistentes sociales estaban a cargo de intentar solucionar las múltiples necesidades de las mujeres; no obstante, las Hermanas del Huerto eran las que mantenían un contacto cotidiano y permanente con ellas. Cumplían una suerte de tarea educativa y evangelizadora; la primera implicaba la enseñanza de "normas de conducta" aceptables para la época, que abarcaban desde aprender a tender una cama (aunque las mucamas se ocupaban de la limpieza de los dormitorios) hasta cómo sentarse a comer en la mesa. También instruían en higiene

\footnotetext{
${ }^{32}$ Ballent, Op. Cit, 67.

${ }^{33}$ Lobato (2005), Op. Cit, 181.

${ }^{34}$ Daniel Lvovich y Juan Suriano, op. cit. pp. 169-195.
} 
personal, puericultura, cocina, costura, limpieza, planchado y pautas generales sobre el cuidado y la salud de la familia. Por medio de la tarea evangelizadora o la "ayuda espiritual" se intentaba corregir aquellas situaciones "anormales", como por ejemplo que una mujer no estuviera casada por Iglesia, que los niños no estuvieran bautizados o que no hubiesen recibido la Primera Comunión. No sólo se impartían sacramentos, sino que también se otorgaba, dentro de las posibilidades, algún tipo de enseñanza religiosa y de buenas costumbres y, por supuesto, de principios morales. Su presencia estaba relacionada con el grupo social al que se deseaba proteger. Ellas se ocupaban de brindarles ayuda moral y religiosa y procuraban por todos los medios "ordenar y reorganizar" sus vidas. En ese sentido, la religión generaba límites, en muchos casos maniqueos. Las prácticas religiosas se presentaban como un servicio social más que brindaba la FEP, y eran cuantificadas y categorizadas como el resto de los servicios prestados en los hogares. De esta manera, compartían la misma jerarquía que una operación médica, un empleo, la entrega de una vivienda, un pasaje o un bautismo. ${ }^{35}$ Los hogares de tránsito se transformaron en un símbolo de la revolución peronista, "la plasmación más real de la justicia social", y de esa manera se los presentaba y exhibía a numerosos visitantes nacionales y extranjeros.

La población objeto de intervención en los hogares de tránsito, en general, se encontraba en condiciones de trabajar, tema que fue central en la protección de las mujeres y sus familias. El trabajo es considerado como un soporte privilegiado de inscripción en la estructura social. ${ }^{36}$ Antes de egresar del hogar se conseguía algún empleo, no sólo para las mujeres, sino también para sus maridos, y los niños en edad escolar, en su mayoría, eran becados. Las mujeres que vivían en el interior se ubicaban en algún empleo, en general el servicio doméstico, conseguido gracias al contacto con las autoridades de las provincias de las cuales provenían y a las cuales se procuró que retornasen. El regreso ayudaría a reconstruir las redes primarias de socialización. De aquí se podría desprender una pregunta para la que aún no logramos conclusiones, y que refiere a cómo se trató el regreso e interacción a estos marcos de protección "comunitaria", porque todo un tejido social se alteró con el paso de esta "experiencia transformadora" que a priori estaba a contramano de las pautas culturales anteriores. Un espacio que idealmente no les habría brindado protección y al que el Estado pretendía después volver.

La especialización, la profesionalización, la institucionalización y la discriminación de las poblaciones a intervenir estructuran la organización del campo social asistencial, señala Castel. A este principio básico, la FEP le incorporó -a título de reivindicación- otros elementos, como residencias lujosas con características singulares y novedosas y una relación particular y especial con la beneficiada. Los hogares de tránsito tuvieron la singularidad de ser instituciones creadas, manejadas, dirigidas por mujeres y para mujeres, y en ellos estaba presente la impronta femenina. Tanto los objetos como los sujetos de la acción social eran mujeres. Unas hacían las veces de transformadoras de las realidades de las otras, pero ni las de un lado ni las del otro escapaban a sus roles culturales: la mujer-madre objeto de intervención y de transformación de las realidades familiares; las asistentes sociales y las religiosas manifestaban una actuación pública que respondía también a sus "condiciones naturales".

\section{Reflexiones finales}

Este trabajo propone el análisis del trabajo femenino explorado desde la óptica de las políticas sociales implementadas por un agente no estatal que tenía a cargo gran parte de ellas, y quizás las más importantes. Más allá de que las políticas sociales son una cuestión de Estado, cuando se plantea una estrategia, éste lo hace pensando en políticas de integración y en suplir deficiencias o déficits que necesariamente deben ser tenidos en cuenta. De allí que la geografía de desigualdades también nos hable, indirectamente, de qué se considera "iguales", es decir, en qué se nivela, hacia dónde, cómo, y con qué carga valorativa. Por eso, cuando se piensa en las

\footnotetext{
${ }^{35}$ Fundación Eva Perón. Memoria. Año 1953.

${ }^{36}$ Castel, op. cit., 15
} 
carencias o lagunas, éstas refieren, también, por contraposición, al conjunto o al todo. Dicho de otra manera, para llenar el vacío es necesario pensar en lo integral. Aquello a lo que se considera déficit o carencia nos indica, también, el tipo de sociedad o, en este caso, de perfil de mujer al cual se está apuntando anclar.

La mayoría de los estudios realizados hasta el momento señalan que las políticas de ayuda social de la FEP estuvieron dirigidas sólo a operar en los márgenes, mientras la política de Estado lo hacía en el centro. Incluso, la misma institución remarcaba este punto de inflexión. Por otra parte, también se buscó matizar la afirmación que indica que la FEP no tuvo una política especial destinada a las mujeres. ${ }^{37}$ De cualquier manera, no podemos dejar de tener en cuenta que las acciones planteadas pueden pecar de ser una gota en el océano.

La bisectriz del trabajo marca una política social según esté o no relacionada con él. Los estudios focalizados en la mujer actúan como puerta de entrada para el abordaje de las políticas sociales, las políticas laborales y la concepción sobre el complejo mundo femenino, que se extiende más allá de lo discursivo y respecto del cual se perciben ambigüedades. Ayuda a indagar sobre el modelo, en el caso que nos compete, de las ansiedades sobre el campo laboral de las mujeres. De allí que del cóctel entre trabajo, maternidad y moral se puedan abrir una serie de cortes que permitan pensar estos temas en nuevas claves. Una mirada transversal sobre los temas en cuestión nos asienta una serie de afirmaciones.

En primer lugar, el corte organizativo realizado por la FEP dista de estar marcado por la bisectriz del trabajo como variable excluyente. La FEP actuó tanto en el centro como en los márgenes y se ocupó de quienes estuvieran, o no, alcanzados por las políticas netamente estatales; situación que potenció la ventaja de implementar "milagrosas políticas" de asistencia social como las caracteriza Lila Caimari. ${ }^{38}$ En segundo término, la FEP tuvo una marcada intención de procurar asistir y proteger a las trabajadoras, y no sólo a las carecientes, a partir de prácticas bien específicas. En algún sentido, se podría vincular esta primera aproximación con los postulados iniciales de la División de Asistencia a la Mujer creada cuando Perón era secretario de Trabajo y Previsión. En tercer lugar, es bien claro que el corte que realiza la FEP en materia netamente laboral está dirigido a mujeres sin hijos, ya fueran éstas las futuras enfermeras o las moradoras del Hogar de la Empleada. El encuadre organizativo de estas instituciones dentro de la FEP fue la matriz de asistencia médico-social. En ese sentido, tanto los hogares de tránsito como el de la Empleada eran considerados instancias de protección social. La protección social de las mujeres implicaba, indirectamente, proteger a quienes tenían familia o planeasen formarla. Es decir, auxiliarlas como centros de sus hogares y como "creadoras del destino del mundo". Esta valoración no era nueva ni exclusiva del peronismo. Si bien la maternidad marca el contenido de las políticas destinadas a las mujeres, las enfermeras se presentan, en principio, ajenas a ese mundo. Las trabajadoras albergadas en el Hogar eran solteras, o al menos no tenían hijos. Aunque sí pensaban en una familia futura, como lo demuestra el cariz moral de la institución como también en el "Piso Blanco" destinado a las jóvenes casaderas. Un espacio para el ensueño dedicado a quienes estaban transitando su camino hacia el vestido de novia.

En cuarto lugar, la única instancia de profesionalización de las mujeres en la FEP -la enfermería- no deja de ser inquietante: si bien se trataba de una actividad que encierra todas las potestades consideradas femeninas, como servir al prójimo, el sacrificio, la abnegación, entre otras, también se percibe una tensión cuando se presenta como una institución con características rayanas a lo castrense y de asociaciones con el mundo masculino. Algún aire de familia encontramos con el discurso artificioso que se implementó en el Partido Peronista Femenino, y es aquel que se construyó intentando suavizar el impacto que generaría el ingreso de las mujeres en la política. ${ }^{39}$ No sabemos si estaba previsto ofrecer algún otro tipo de profesionalización para las mujeres en la FEP, sólo contamos con la enfermería, que, según

\footnotetext{
${ }^{37}$ Marysa Navarro, op. cit.

${ }^{38}$ Lila Caimari, Perón y la Iglesia Católica. Religión, Estado y sociedad en la Argentina (1943-1955), Ariel (Buenos Aires 1995).

${ }^{39}$ Barry, (2009) op. cit. 156.
} 
refiere quien fuera su regente, estaba pensando expandirse a las provincias. ${ }^{40}$ La pregunta que surge es qué hubiera sucedido si la existencia de la FEP se hubiera prolongado. Qué hubiera sucedido si un importante número de mujeres hubiesen sido entrenadas como las enfermeras de la FEP, más allá de los aspectos netamente sanitarios.

La Fundación se presenta como un espacio de trabajo casi netamente femenino, donde numerosas mujeres ocuparon puestos de distinto tipo y jerarquías. Se podría aseverar que se trató de una institución de mujeres para mujeres en sentido amplio. Además, la decoración de sus instituciones apelaba a una determinada imagen para la cual lo femenino no pasaba desapercibido. ${ }^{41}$

Ahora bien, en el texto me he detenido, especialmente, en las políticas aplicadas sobre quienes se encontraban no sólo por fuera del mundo laboral sino en un estado de exclusión y pobreza extrema. La FEP operó en este caso sobre las mujeres con o sin hijos, es decir, la maternidad no era privativa para ingresar en este espacio, aunque muchas de ellas fueran madres. La pregunta que guió el abordaje fue qué implicaba incluir o asistir o proteger socialmente a la mujer. No hay una forma única de intervención social y, en ese sentido, la FEP, tal como he señalado a lo largo del presente trabajo, constituyó una alternativa que concluyó pronto, pero su trascendencia ha sido formidable.

Las estrategias utilizadas fueron peculiares, y sus características, distintivas. La premisa parecía ser: la carencia se enmienda con la abundancia. Los objetos de lujo, la decoración, la indumentaria, la nutrición, la sanidad, la relación entre benefactora y beneficiada, la individualización de cada caso y la religión fueron puntales de las políticas de protección e igualación social femenina. De allí surge una nueva pregunta: ¿con el peronismo, ciertos lazos de interdependencia (los contextos "cercanos" de que habla Castel) se habrían debilitado y habrían sido reemplazados por otros? Los varones no contaron con un sistema de protección equivalente al de los hogares de tránsito femeninos, lo que supuso una discriminación por sexos, por necesidades sociales y sobre quiénes era perentorio asistir. Si bien las mujeres se presentaban como receptoras pasivas de la ayuda destinada a "mejorar sus vidas", el hecho de que se pusiera el énfasis en ellas las colocaba como potenciales operadoras del cambio en el hogar, como promotoras de dinámicas transformaciones sociales.

El fin de los hogares de tránsito se transformó en una manera singular de "ordenar" u "organizar" a la familia, empezando por la madre, a quien se le otorgaba un papel transformador. Es decir, la mujer, sujeto de intervención, actuaba como un motor de cambio, y por su intermedio se intentaba dar inicio a una nueva etapa de la vida familiar. La ayuda a las madres no implicaba la existencia de una política pro natalista, sino más bien una política destinada a fortalecer a la familia como fruto de sentimientos y representaciones de buena parte de la sociedad argentina, como señala Dora Barrancos. ${ }^{42}$ Consolidar la vida familiar aparece como la estrategia más económica de la supervivencia de los sectores más pobres, entre quienes los lazos de solidaridad y ayuda mutua permiten aliviar la carga del Estado; ${ }^{43}$ de allí el énfasis por normalizar las situaciones de hecho. A esto se suma que la madre es un agente de salud por excelencia. Los hogares se presentaban como una suerte de pasaporte a una "segunda oportunidad", que era insuficiente si no se alternaba con otro servicio social más: inculcar valores morales católicos, indispensables para encauzar la vida de una mujer y cumplir con su misión sagrada.

El trabajo tomado como bisectriz de las políticas sociales aplicadas a las mujeres por la FEP se encuentra a su vez teñido por la moral, el virtuosismo y la necesidad de protección y tutela de estas mujeres, mientras la política también se filtraba; pero, deliberadamente, la he dejado de lado en este artículo. Quizás, muchas de las improntas destinadas a cuidar a la mujer pudieron tener correlación con otras instituciones similares de periodos anteriores. Entonces,

\footnotetext{
${ }^{40}$ Álvarez, María Eugenia, La Enfermera de Evita, Inhiep, (Buenos Aires 2010).

${ }^{41}$ Anahí Ballent, "El Lenguaje Del Bilbelot". En Barry, op. cit.181.

${ }^{42}$ Dora Barrancos, Iniciativas Y Debates En Materia De Reproducción Durante El Primer Peronismo (1946-1952), Seposal-Gredes-Unsa, (Salta 2001).

${ }^{43}$ Castel, Op. Cit. 41.
} 
¿qué fue lo innovador del peronismo? Acaso, la alteración profunda de las estructuras de asistencia social, en tanto las agendas futuras se verían en la obligación de tomar en cuenta esta experiencia. No es menor el tema de que estas políticas no fueran de la mano del gobierno o del Estado, responsable principal de llevarlas a cabo, sino de una institución privada conducida por una mujer que no ocupó ningún cargo formal dentro del gobierno, pero que llevó a cabo políticas estatales por fuera del mismo Estado. Quizás, se trató del preámbulo de ingentes innovaciones reales y simbólicas que marcaban una tensión entre el discurso y la práctica, más allá de la valoración de la mujer. Pero también sería un punto de inflexión sobre la construcción de una cultura política que perdura, que no rompe con las instituciones democráticas, pero que mantiene una posición resbaladiza frente a sus cánones. 